\title{
USING UAV-BASED 3D IMAGES OF INDIVIDUAL TREE SPECIES IN DISTANCE EDUCATION IN FORESTRY
}

\author{
Zennure Uçar ${ }^{1 *}$, Abdullah Emin Akay² \\ 1'̇zmir Katip Çelebi University, Faculty of Forestry, 35620 Çiğli, İzmir, Turkey - zennure.ucar@ikcu.edu.tr \\ ${ }^{2}$ Bursa Technical University, Faculty of Forestry, 16310 Yıldırım, Bursa, Turkey
}

\section{Commission VI, WG VI/4}

KEY WORDS: 3D images, SfM, UAV, Individual tree detection, Distance education, Forestry

\begin{abstract}
:
Distance education has been offered for years, but the integration of technological developments and opportunities into education has recently increased its popularity and event it became an indispensable method during the Covid-19 pandemic period. In distance education, accessing all class materials such as lecture presentations, class notes, reading materials, videos, live chats or class hours, and archive records allow students (participants) to learn without being in the same environments with teachers or learners. Technology has made vast contributions to the field of education. For instance, 3D as a teaching tool for the class attracts students' attention, makes the learning process more enjoyable, and increases participation. In particular, for the disciplines, such as forestry, earth, and environmental sciences, which require laboratory exercises, field observation, field trips, and in-situ measurements, 3D modeling has provided many benefits in distance education. It enables 3D demonstration of the individual tree species to develop a virtual field laboratory. This study focused on the data sources and techniques to generate a 3D model of the individual tree species that forestry students used for distance education. The capabilities of the method in the generation of 3D models were evaluated by using UAV-based SfM photogrammetry. The results indicated that implementing 3D images of individual tree species can be a promising method that may increase the interest, interaction and satisfaction of the students in distance education in forestry.
\end{abstract}

\section{INTRODUCTION}

The use of aerial photographs and satellite images is quite common in the field of forestry. High-resolution satellite images or aerial photographs can be unsuitable for the researcher in terms of cost and time consumption; therefore, Unmanned Aerial Vehicles (UAV) are considered an economical and practical tool that turns the concepts of time and space in favor of the researcher. UAVs provide high mobility, flexibility, security, programmability, time, and cost-effectiveness. Thus, they are highly preferred as a remote sensing tool among today's alternatives (Wing et al., 2014). mounted on the UAV, have been used in many civilian applications such as forestry activities, precision agriculture studies, meteorology, rescue activities, wildlife research, building control, traffic monitoring, natural disasters, and landscape planning (Shahbazi et al., 2014).

UAVs, also called "drones," have become widespread worldwide due to the commercial approaches of companies mainly from Canada and China. Depending on the type of aerial platform used, four main UAV types are used for non-military purposes: Multi-Rotor, Fixed Wing, Single Rotor, and FixedWing Hybrid VTOL (Figure 1).

Many UAVs brands and models come with systems that include various sensors for different users' purposes. These systems,

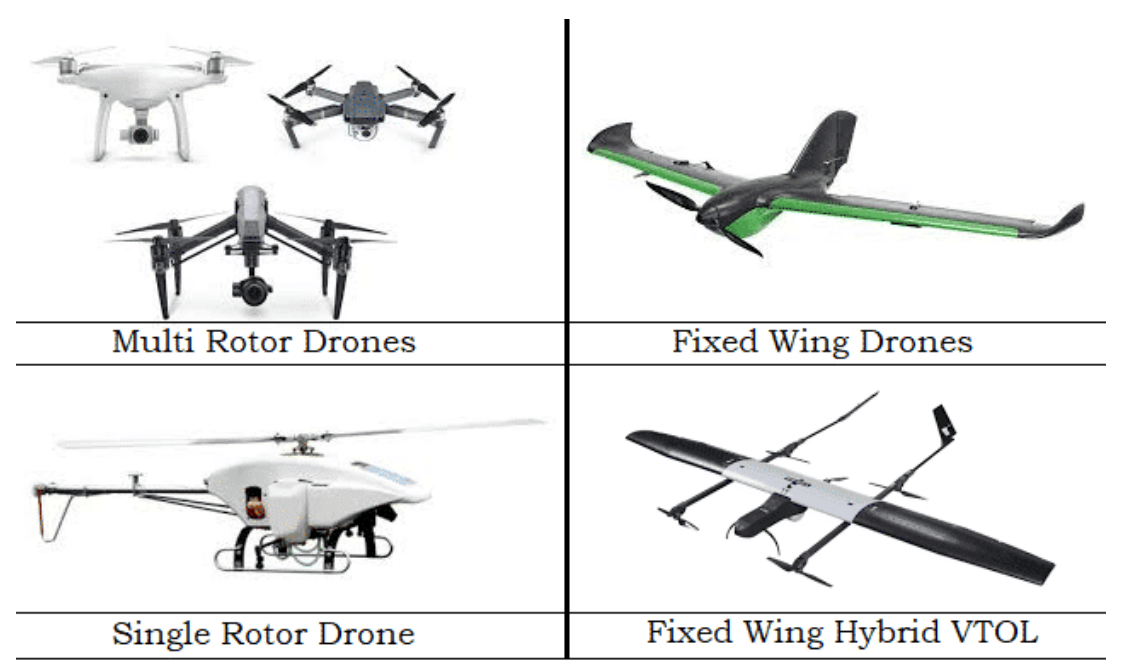

Figure 1. UAV types 
a) Multi-Rotor: Multi-Rotor UAVs are the most common types of UAVs used by professionals and hobbyists. The major advantage of these drones is that they can take off and land vertically. In this way, it does not need any platform for take-off and landing.

b) Fixed Wing: These drones are completely different from multi-rotor drones in design. They have 'wings' like regular airplanes. Unlike multi-rotor UAVs, fixed-wing type models never use energy to stay afloat while fighting gravity. Instead, they proceed along the designated route as long as their energy sources (battery) allow.

c) Single Rotor: These UAVs are similar to real helicopters in terms of design and structure. Unlike a multi-rotor UAV, a single rotor model has only one large-size rotor and a small-size rotor at the tail of the UAV to control its direction. Single-rotor UAVs are much more efficient than multi-rotor versions.

d) Fixed-Wing Hybrid VTOL: They are hybrid versions that combine the advantages of fixed-wing models (higher flight time) with the advantages of rotor-based models (floating). With the advent of a new generation of sensors (gyroscopes and accelerometers), this concept has taken a new direction.

It is possible to develop data such as digital terrain model (DTM) and digital surface model (DSM) using photographs obtained from UAVs. Images taken from UAVs come to the fore, especially when altitude data is required. It is cheaper and more practical to generate DEMs from UAV data when compared to high-precision LiDAR data (Büyüksakallı and Akay, 2019). Besides, the limited availability of LiDAR data on forest areas makes UAV uses important in forestry activities. The addition of advanced GPS systems to UAVs allows terrestrial measurements from UAV images, can produce highly accurate spatial data.

The digital elevation models can be produced in raster data or point cloud data by using the images obtained from UAVs. The accuracy and the quality of the DEM and three-dimensional model can be affected by characteristics of the camera mounted on UAV, such as positional accuracy, sensitivity, resolution, depending on the sensor, or other factors like overlay rate, flight speed, and battery life.

After the UAV flight is completed, the images are processed in the office environment to obtain altitude data. Height $(\mathrm{Z})$ data are used in developing three-dimensional terrain models and digital elevation models, which is an important issue for forestry (Iglaut et al., 2019). The Structure from Motion (SfM)-based photogrammetry is a widely used method to derive the tree parameters such as tree height, canopy volume, and trunk diameter (Gülci, 2019; Gülci et al., 2021). UAV-based SfM method, which provides a great potential for forest practitioners and researchers, enables surveys with low cost and high accuracy. Besides, point clouds data generated from highresolution UAV imagery using the SfM method can be effectively used in the 3D modeling of individual tree species.

\section{USING UAV-BASED SFM METHOD FOR 3D MODELING OF INDIVIDUAL TREE}

The SfM method is based on the principle of changing the binocular vision of a moving object (Koenderink and van Doorn, 1991). Using the SfM method, 3D models can be developed automatically from sequences of overlapping 2D images without consistency of images, camera pose, and calibrations (Fonstad et al., 2013). In the recent decade, UAVbased SfM data have been used to estimate tree parameters such as height, diameter, volume, and biomass (Dandois and Ellis, 2013). In the applications, a series of overlapping images are taken around a tree, uploaded to a computer, aligned by photogrammetry software, and reconstructed to produce a 3D model of the tree. The circular flight around the target tree can provide detailed imaging, resulting in a dense point cloud model (Moreira et al., 2021). Agisoft Photoscan is one of the most widely used software for processing UAV data. This software provides a user with a quick and accurate generation of $3 \mathrm{D}$ point cloud to extract individual tree modeling (Figure 2).

When the Agisoft Photoscan program is opened, various application tools appear on the interface. The "Workspace" area is used to process the photographs. After selecting the relevant coordinate system, the drone-derived images are opened in the "Workspace" area. After that, they are aligned according to their common points with the "Align Photos" tool located under the "Workflow." At this stage, a point cloud (Tie Points) is produced from the common points. Then, Tie Points are used in the next step called "Dense Cloud."

"Dense Cloud" is a stage that requires high processing power; therefore, a high-performance computer should be used at this stage. Once the "Dense Cloud" is ready, the aerial photos appear to be one piece; however, the point cloud can be clearly distinguished when zoomed in. In the next step, the triangular (TIN) model can be generated with the "Build Mesh" tool. The TIN model provides the surface formation with triangles formed from the points. In the following stage, the images can be displayed in three dimensions using the triangular model. The three-dimensional DEM can be produced with the "Build Tiled Model" tool under "Workflow." At this stage, either the previously produced triangular model or dense point cloud can be used. The last stage, which also requires processing power, is the production of three-dimensional models. The 3D models can be produced in various quality, but if the high-quality model is desired in detail, this process takes more time in computers with low processing power and insufficient memory.

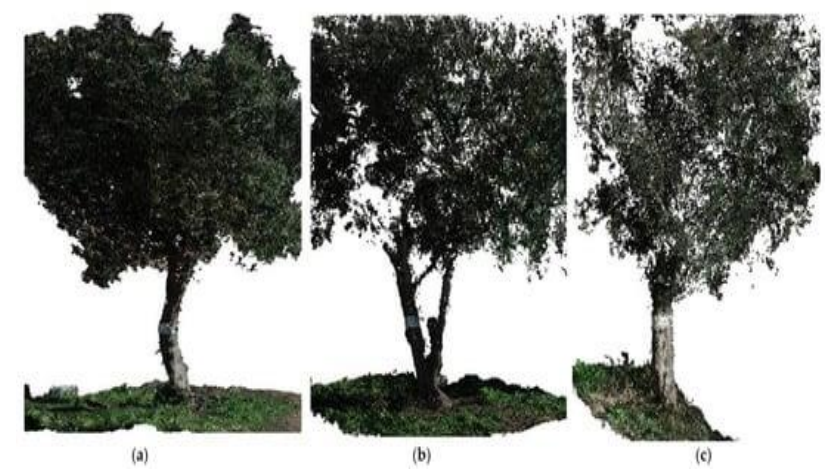

Figure 2. 3D point clouds of sample trees surveyed by the circular flights (Moreira et al., 2021)

While capturing the data, UAV first rises above the starting point to a user-specified height and then moves horizontally to the beginning of the flight, completes the mission, and returns to the starting point. The pre-determined flight path should be free of any other objects, and the target should be centered on the images. There are various UAV trajectories for image acquisition, including (Gatziolis et al., 2015): 
- circular at constant height (a),

- stacked circles each at different above-ground height, for tall trees (height $>20 \mathrm{~m})(\mathrm{b})$,

- $\quad$ spiral for trees with complex geometry (c),

- vertical meandering targeting tree sectors (d),

- clover for trees with wide ellipsoidal tree crowns (e),

- spring-hemisphere designed for trees with flat-top, asymmetrical crowns (f),

- $\quad$ nested circles centered on the tree $(\mathrm{g})$,

- jagged saucer designed for trees with dense foliage but low crown compaction ratio $(h)$.

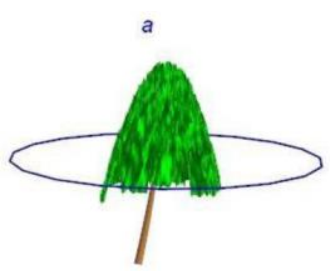

c
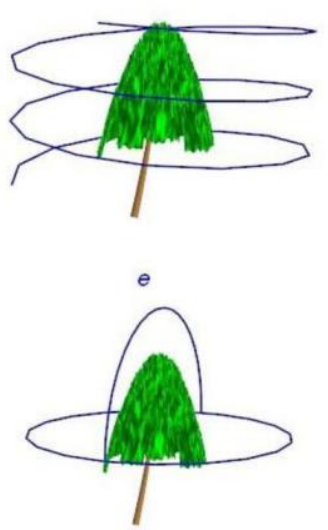

$g$

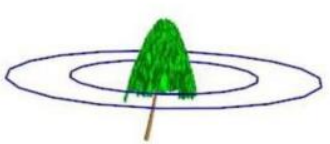

Figure 3. UAV trajectories for image acquisition (Gatziolis et al., 2015)

A complete tree reconstruction can be produced after the UAV flights. Even the shaded parts of the tree crown can be represented by using circular flight. The comprehensive tree reconstructions are possible using UAV-based images of the tree (Figure 4). GPS-equipped UAVs should be used in data capture to better scale 3D tree models to actual dimensions. The accuracy of the tree reconstruction depends on the overlap ratio selected during the flight plan. Previous studies suggested that $70 \%$ overlap is sufficient for accurate 3D tree models as more than $70 \%$ overlap does not improve the accuracy of tree reconstructions (Gatziolis et al., 2015). Compared with the synthetic imagery generated by the LiDAR point cloud, UAVbased imagery provides cost-efficient and accurate solutions to object reconstructions problems.
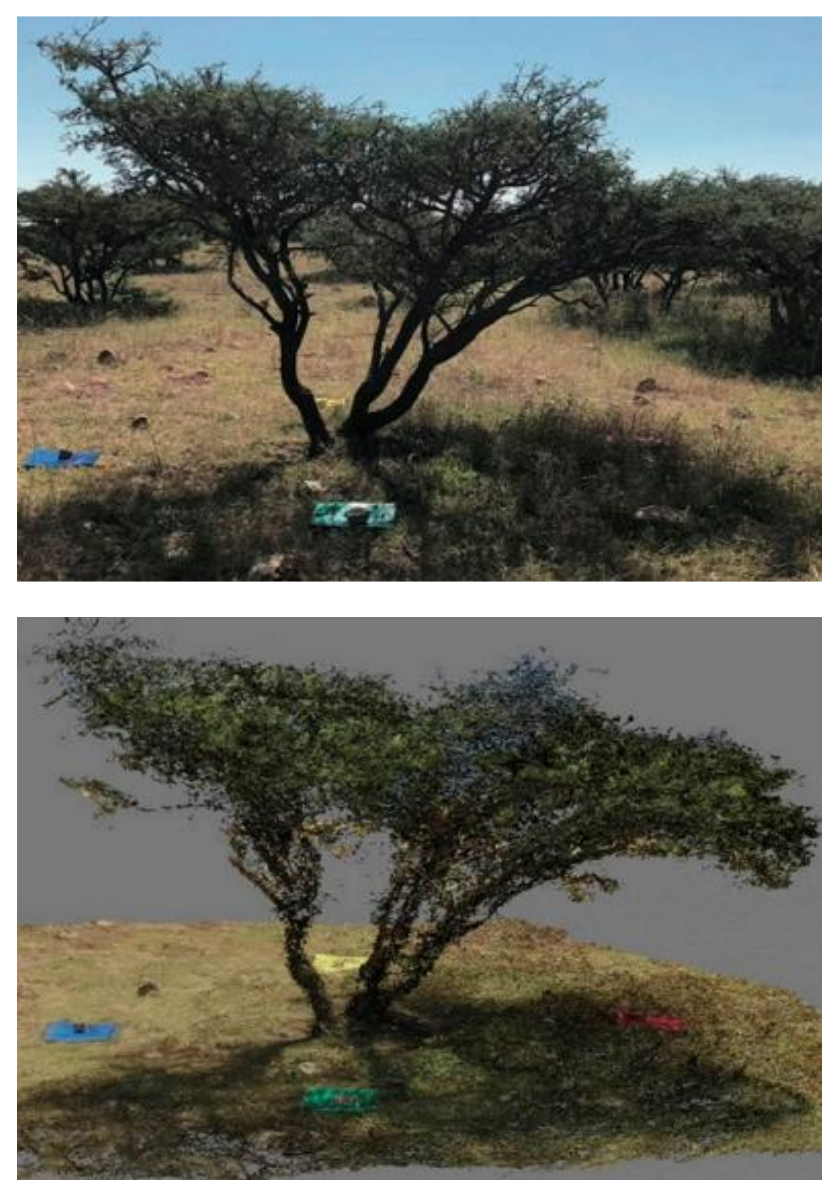

Figure 4. A reconstruction of sample tree (above) based on a UAV-derived point cloud image (below) (Sakai et al., 2021)

\section{UAV-BASED 3D IMAGE OF INDIVIDUAL TREE FOR DISTANCE EDUCATION IN FORESTRY}

In recent years, distance education has increased its proportion in higher education in the world. In particular, it can be considered as the essential education method during the Covid19 pandemic period. Due to the developments in information technologies and new concepts in higher education, students can access class materials such as lecture presentations, notes, reading materials, and videos. Those archive records and live courses via well-developed online distance education programs allow students to pursue higher education without physically being in the classroom with teachers. Thus, distance education can be defined based on four main features: exchanging data, sound and video, interactive telecommunication, corporate basis, and separation of teacher and student (Simonson et al., 2008).

On the other hand, distance education in natural resourcesrelated fields such as forestry may face unique problems and challenges as they require both laboratory exercises and field trips and in-situ measurements in some of the course work. One of the most critical challenges is identifying tree species which is a critical issue for forest management and planning, therefore, for higher education in forestry. The main characters used to identify trees include leaves, needles, flowers, fruits, and barks. Besides, each tree species has a unique shape and form; thus, the shape and form are another crucial distinguishing feature of a tree species, especially from a distance. Tree species identification course requires both laboratory exercises and experimental works in the field. 
Using 3D visualization of objects associated with the classwork has great potential to improve the motivation, satisfaction, performance of the students in the classroom and increase their participation during the courses. The previous research stated that providing a high level of interaction is the key factor in distance education (Kearsley, 2000; Kuo et al., 2014; Kauffman, 2015). 3D technology contributes to class interactions, which are crucial for effective learning during distance education. Indeed, implementing the interaction model in distance education helps students gain more knowledge effectively (Nandi et al., 2015). For example, Birt et al. (2017) used 3D printed objects for paramedic distance education. The results showed statistically significant improvement compared to conventional methods. AbouHashem et al. (2015) and Garcia et al. (2017) conducted a study related to the application of 3D printing materials in medical education. They stated that 3D modeling, and 3D printing of an object represent helpful educational tools. Students can both access obtained 3D images of objects and print them if they have appropriate equipment (printer). Thus, the student will have a chance to examine even a rare and fragile element, which are not available previously for inspection, in 3D model images or 3D model prints. Similarly, 3D modeling of the individual tree species can turn distance education into a virtual field laboratory.

There are mainly three interaction alternatives: student-content, student-student, and student-teacher (Tonguç and Özkara, 2020) (Figure 5). Students can access the pre-developed archive in student-content interaction and observe a 3D demonstration of the trees generated based on the UAV-based SfM photogrammetry. Student-student interaction is also critical in terms of sharing ideas, knowledge, and experiences in distance education. Finally, student-teacher interaction can positively affect the inspiration, response, and performance of the students (Andserson, 2003).

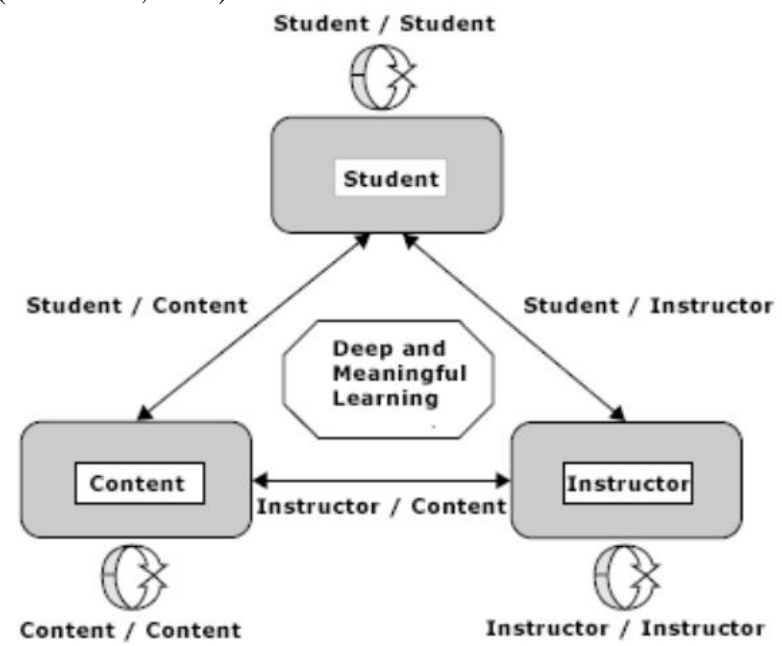

Figure 5. Interaction alternatives in distance education (Anderson, 2003)

\section{CONCLUSIONS}

Advances in information technologies have made it possible to use technological tools in many sectors, including distance education. The students' perceptions about the type of distance education tools are vital as it affects students' performance. For example, 3D as an education tool receives the students' attention and makes distance learning pleasant. 3D modeling of tree species has provided many benefits to distance education in forestry as it requires laboratory exercises, field observation, and field trips. This study aimed to evaluate the data sources and techniques to generate a 3D model of the individual tree species used for distance education forestry students. The capabilities of the UAV-based SfM photogrammetry in the generation of 3D models were assessed. It was realized that the 3D model of tree species provides a highly innovative contribution to both technical and practical aspects of higher education in forestry.

Using 3D demonstration of tree species in distance education requires a high-capacity server, enough side storage units, high speed internet connection, and necessary space for students in the server. Even though necessary technology used in distance education may not be readily available and freely accessible, it is highly predicted that $3 \mathrm{D}$ models of class objects in forestry education will be widespread in the future as the technology improves in distance education.

\section{REFERENCES}

AbouHashem, Y., Dayal, M., Savanah, S., Štrkalj, G. (2015). The application of 3D printing in anatomy education. Medical education online, 20(1), 29847.

Anderson, T., 2003. Modes of interaction in distance education: Recent developments and research questions. Moore M.G. and Anderson W.G (Eds.), Handbook of distance education, pp.129144. New Jersey.

Birt, J., Moore, E., Cowling, M. (2017). Improving paramedic distance education through mobile mixed reality simulation. Australasian Journal of Educational Technology, 33(6).

Büyüksakallı, H., Akay, A.E., 2019. Generating Canopy Height Model of a Stone Pine (Pinus Pinea) Stand Using UAV Imagery. V. Science Technology and Innovation Congress, 1721 April, Alanya, Antalya.

Dandois, J.P., Ellis, E.C.., 2013. High spatial resolution threedimensional mapping of vegetation spectral dynamics using computer vision. Remote Sens Environ. 136, pp.259-76.

Fonstad, M.A., Dietrich, J.T., Courville, B.C., Jensen, J.L., Carbonneau, P.E., 2013. Topographic structure from motion: a new development in photogrammetric measurement. Earth Surf Process Landf. 38, pp.421-30.

Garcia, J., Yang, Z., Mongrain, R., Leask, R. L., Lachapelle, K. (2018). 3D printing materials and their use in medical education: a review of current technology and trends for the future. BMJ Simulation and Technology Enhanced Learning, 4(1).

Gatziolis, D., Lienard, J.F., Vogs, A., Strigul, N.S., 2015. 3D Tree Dimensionality Assessment Using Photogrammetry and Small Unmanned Aerial Vehicles. PLoS ONE 10(9): e0137765. https://doi.org/10.1371/journal.pone.0137765

Gülci, S., 2019. The determination of some stand parameters using SfM-based spatial 3D point cloud in forestry studies: an analysis of data production in pure coniferous young forest stands. Environ. Monit. Assess, 191, 495.

Gülci, S., Akay, A.E., Gülci, N., Taş, İ., 2019. An assessment of conventional and drone-based measurements for tree attributes in timber volume estimation: A case study on stone pine plantation. Ecological Informatics, 63(2021). 
Iglhaut, J., Cabo, C., Puliti, S., Piermattei, L., O’Connor, J., Rosette, J., 2019. Structure from motion photogrammetry in forestry: A review. Current Forestry Reports, 5(3), pp. 155-168. Kauffman, H., 2015. A review of predictive factors of student success in and satisfaction with online learning. Research in Learning Technology, 23.

Kearsley, G., 2000. Online education: Learning and teaching in cyberspace. Wadsworth Publishing, USA.

Koenderink, J.J., van Doorn, A.J., 1991. Affine structure from motion. J Opt Soc Am A. 8, pp.377-85.

Kuo, Y.C., Walker, A.E., Schroder, KE., Belland, B.R., 2014. Interaction, internet self efficacy, and self-regulated learning as predictors of student satisfaction in online education courses. The Internet and Higher Education, 20, pp.35-50

Moreira, B.M., Goyanes, G., Pina P., Vassilev, O., Heleno, S., 2021. Assessment of the Influence of Survey Design and Processing Choices on the Accuracy of Tree Diameter at Breast Height (DBH) Measurements Using UAV-Based Photogrammetry. Drones. 5(2), pp. 43.

Nandi, D., Hamilton, M. and Harland, J. (2015). What factors impact student-content interaction in fully online Courses. International Journal of Modern Education and Computer Science, 7(7), pp.28-35.

Sakai, T., Birhane, E., Abebe, B., Gebremeskel, D. 2021. Applicability of Structure-from Motion Photogrammetry on Forest Measurement in the Northern Ethiopian Highlands. Sustainability, 2021, 13, 5282.

Shahbazi, M., Théau, J., Ménard, P., 2014. Recent applications of unmanned aerial imagery in natural resource management. GIScience \& Remote Sensing, 51(4), pp. 339-365.

Simonson, M., Smaldino, S., Albright, M., Zvacek, S.M., 2008. Teaching and learning at a distance: Foundations of distance education. Information Age Publications, Chorlatte, North Carolina.

Tonguç, G., Özkara, B.Ö., 2020. Using 3d Hologram in Distance Education. Turkey Education Journal, 5(1): 56-68

Wing, M.G., Burnett, S., Johnson, S., Akay, A.E., Sessions, J., 2014. A Low-cost unmanned aerial system for remote sensing of forested landscapes. International Journal of Remote Sensing Applications. 4(3), pp. 113-120. 